\title{
Reconstruction or Reuse? How Real Estate Values and Planning Choices Impact Urban Redevelopment
}

\author{
Alessia Mangialardo * and Ezio Micelli ${ }^{D}$ \\ Department of Architecture and Arts, IUAV University of Venice, I-30123 Venice, Italy; micelli@iuav.it \\ * Correspondence: amangialardo@iuav.it
}

Received: 16 April 2020; Accepted: 6 May 2020; Published: 15 May 2020

\begin{abstract}
Local administrators and private investors rely on various urban redevelopment strategies, the choice of which depends on the economic expectations of property owners and investors. Some of these options foresee replacing obsolete buildings with new constructions; others prefer the reuse of existing assets. This study examines the conditions that make these different strategies feasible, bringing to light the aspects that favor demolition and reconstruction processes over interventions based on the redevelopment of existing assets. The analysis focuses on the variables that determine the choice between these two options. The model that has been developed highlights, on one hand, the role of urban planning tools and urban densification and, on the other, the relationship between the land market and the value of existing assets. The model has been tested on five cities in northern Italy, which fall into three territorial categories-large metropolitan cities, medium-sized cities, and cities of limited rank-to test how different social and economic contexts affect the feasibility of the strategies we evaluated. The results of the study underscore the extent to which the demolition and reconstruction of existing assets is only viable in certain limited areas and under particular market and settlement conditions. While large metropolitan areas seem to have the option of radically replacing existing real estate assets, medium-sized cities and especially small cities are constrained in redeveloping existing urban assets and must forego demolition and reconstruction projects, which do not prove to be economically feasible.
\end{abstract}

Keywords: urban reuse; reconstruction and demolition; upcycle; retrofit construction industry

\section{Introduction}

Sustainable urban development requires the city to be renewed without consuming additional non-urbanized land. Yet, even though the goal of regenerating the existing city has been high on national and international administrative agendas for some time, the methods and tools by which the built environment can be transformed have remained more problematic [1,2].

Local administrators and private investors rely on various urban regeneration strategies, the choice of which depends on economic feasibility and the expectations of property owners and developers. One option that is often discussed is the demolition of the existing city and the replacement of obsolete assets through new construction. Other more conservative strategies foresee the reuse of existing assets by upcycling obsolete real estate, drawing out the material, energy, and social value still inside the existing building stock [3].

The choice between these two options depends on certain economic assumptions that have not yet been thoroughly analyzed. This study seeks to further investigate the conditions that make the regeneration of the existing city feasible, bringing out factors that favor demolition and reconstruction processes over interventions based on the reuse of existing assets.

To this end, a model developed by the authors in previous research [4] assesses the economic advantages of reusing the existing building stock, compared to demolition and reconstruction operations. 
The model analyzes some Italian cities, which greatly vary in the size and magnitude of their real estate market. The model focuses on the real estate market and does not consider strategies and operations carried out by public administrations. Furthermore, the research focuses only on the local by-laws concerning, in particular, planning rules that affect the crucial variable of building density.

The paper has six sections. The first presents the debate on the regeneration of the existing city and the terms of the research. The second focuses on the theoretical model used to identify the advantages of the reuse option compared with demolition and reconstruction. The third tests the model on five Italian cities: Milan, Turin, Padua, Novara, Udine. The fourth analyses the data, while the fifth presents an interpretation of the results of the investigation. The conclusion summarizes the goal and results, as well as suggesting future research developments.

\section{Demolition and Reconstruction vs. Recycling: Economic Alternatives to Urban Reuse}

Urban regeneration and land use containment are two priorities of Italian and international territorial policies $[5,6]$. One of the main objectives central and local authorities pursue is the transformation of already urbanized areas to make existing cities more compact, therein lowering the collective costs related to urban sprawl and the consumption of non-urbanized land [7-9]. Inefficiencies linked to urban sprawl contribute to the systematic use of private vehicles and, therein, to air pollution [10]. They also increase costs related to public services, such as roads, parking, and infrastructure in general [11-14]. On the contrary, denser cities improve mobility, lower per capita infrastructure costs, and curb the use of scarce, non-reproducible resources $[9,13,15]$.

While upgrading the existing city appears to be a priority, the ways in which it can be transformed are less clear. There are two possible scenarios. The first is through the demolition and reconstruction of existing buildings and neighborhoods. The second is to upscale existing assets through strategies aimed at enhancing the value of the existing building stock [16-18]. The choice between these two options is widely debated by academicians and scholars worldwide. Additionally, scholars and professionals also widely debate this choice. In particular, the literature analyzes the issue from three points of view: environmental sustainability, production costs, and social impact. The methodologies comparing the two alternatives differ. Some of them are based on case studies and present the financial performances of the investments. Some compare the two options valuing the non-monetary effects of the interventions focusing, in particular, on energy and materials costs.

From an environmental perspective, the sustainability of urban redevelopment is linked to the possibility of upscaling existing buildings starting from the material and the energy they still contain [19-21]. The extraction of raw materials and the energy consumed in building production creates additional environmental pollution and climate-altering gases [22,23]. Demolition and reconstruction are less environmentally friendly: $20 \%$ of toxic waste comes from demolition, and most of the toxic materials are thrown into landfill without being properly recycled [24]. Reducing the extraction of raw material and energy consumption through the reuse of existing assets is a new frontier for aligning the building industry with the principles of a circular economy [25-30].

In terms of the cost of these interventions, some researchers argue that, under certain conditions, the reuse of existing buildings is more cost-effective than demolition and reconstruction $[5,18,21,31]$. Regular building maintenance and renovation can significantly reduce building degradation and obsolescence over time. Furthermore, these operations have significantly lower costs than those of extraordinary restructuring $[5,21,27,31,32]$, and some scholars measure the economic advantages of urban reuse through financial analysis [33,34] or statistical methodologies [35-38]. This issue, however, remains controversial because the assumptions underlying the expediency of reuse are tricky.

One problem is the constancy building maintenance requires. If buildings are neglected for several years, the costs of delayed maintenance are similar to or even higher than those of demolition and reconstruction. Moreover, when a building has high energy, structural, and functional deficiencies, the costs of its recovery increase significantly, determining conditions that are more favorable to radical interventions $[5,21,27]$. 
Finally, regarding the social impact of these two options, demolition and reconstruction operations force occupants to relocate, complicating these interventions and inevitably resulting in a loss of social capital. New buildings usually prompt an increase in real estate value that excludes prior occupants who are now unable to afford the new buildings. In addition, relocating building occupants from areas subject to demolition and reconstruction generates domino effects on other buildings in the district $[13,29,39]$.

Whereas the issues regarding the importance of recycling the existing city have been examined in depth, the economic conditions capable of promoting regeneration processes have not yet been fully explored. It is still important to analyze the interests that mobilize urban transformation projects, both in terms of ownership and in terms of the players involved in the development process. It is important to not only measure the cost-effectiveness of the private investor against the costs of demolition and reconstruction or reuse.

Most of the literature analyses the different aspects of cost-effectiveness between demolition and reconstruction or reuse through ex-post surveys with both qualitative and quantitative methodological approaches. We believe it is relevant—and not yet debated in the literature-to adopt a deductive approach that questions the fundamental aspects of the urban economy. Our purpose is to assess whether the actual building capacity expected by local authorities in demolition and reconstruction work is sufficient to repay the considerable costs incurred by a private investor. In other words, what is the urban planning premium that a local authority must give in order for a private investor to consider it worthwhile to demolish and rebuild an existing building?

The importance of this sort of scrutiny is clear. Urban policies guide the existing city's transformation, and urban planning tools are essential to the effectiveness of these policies. Urban planning choices help determine land values and can be directed toward one or another form of reuse. In Italy, there are still no urban planning regulations on a national scale. Many municipalities have begun to encourage demolition and reconstruction operations by favoring building premiums-usually not exceeding $30 \%$ of the existing volume, in keeping with Veneto region's law Piano Casa-in exchange for interventions carried out according to the highest criteria of environmental and energy sustainability.

Within the sectors of the urban economy, it is land value — and thus land rent [40]—-that determines property owners' and developers' choices. As such, the terms under which real estate may be redeveloped determine the reasons for the choice of reuse strategies. More precisely, if the development permitted under the urban plan justifies the demolition of buildings or entire districts because the potential benefits are higher than the buildings' residual value, property owners will consider demolition and reconstruction a rational choice. On the contrary, where prospects for land development cannot exceed the value of existing assets, the economic reasons for demolition and reconstruction diminish, and strategies for regenerating existing assets are more advantageous.

To answer the research question, the authors have taken three steps. First, a theoretical model, previously developed [4] and refined for this research, is explained. Second, the authors implemented the model with the real estate values of five Italian cities. Finally, they interpreted the results of the tests (see Figure 1). 


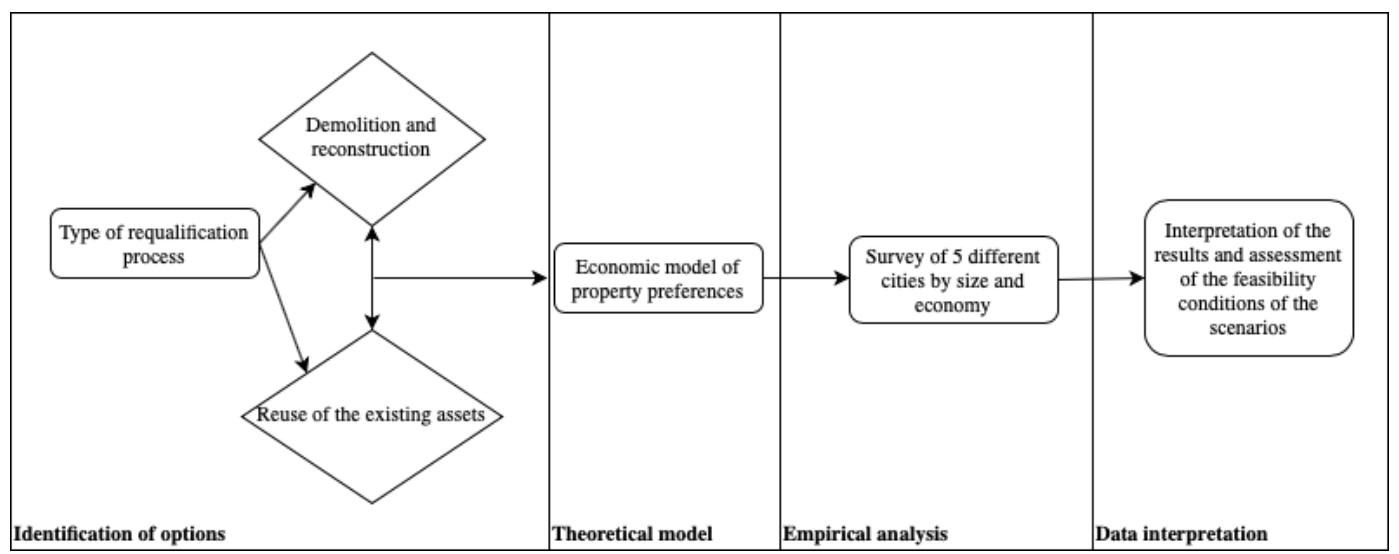

Figure 1. Schematization of the procedure used in the writing. Source: authors' elaboration.

\section{The Model: How to Evaluate the Two Possible Scenarios}

Should a property be redeveloped by means of demolition and reconstruction, or is the reuse of the existing asset more economically viable? The answer depends on the conditions that urban planning tools impose and on real estate market values. Owners evaluate the highest and best use of their assets and consider it advantageous to sell their property to a developer interested in demolition and reconstruction [4] if (1)

$$
\mathrm{Vp}>\mathrm{Ve}
$$

where $\mathrm{Vp}$ is the value of the building rights established by urban planning regulations, and Ve represents the value of existing buildings.

For the purpose of simplification, the transaction costs related to the acquisition of real estate assets and their availability are considered null. It should be noted that this is often far from the case: if a developer purchases a building with a number of different owners, he/she will have to make the often non-negligible effort of unifying the properties, bearing all the costs involved. All the same, in verifying the expediency of the provisions established to promote demolition and reconstruction processes, it seems useful to proceed on the assumption of the absence of transaction costs. Although the results obtained from the model underestimate the total volume required to create conditions that are advantageous to property owners, these values are still useful in determining the building density required in order to transform the city through demolition and reconstruction.

The value attributed by the building index depends on the development potential of the area and its market value. The value of existing buildings is the product of the marketable surface area and the unit market value of the assets.

The inequality can be developed as follows (2):

$$
\text { a ip Vmt > S Vme }
$$

where, in the first member, a represents the area subject to redevelopment, expressed in square meters; ip represents the building to land ratio, which is an essential urban planning ratio that defines the building capacity of a particular parcel of land, with a direct impact on its economic value; and Vmt indicates the value of the building potential. In the second member, $\mathrm{S}$ is the area expressed in terms of the gross marketable area of existing building units, and Vme indicates the unit market value of existing properties.

The market value of the land to be developed can be derived from the value of the newly constructed buildings. The market value of new or perfectly renovated buildings is related to the value of the land by a ratio herein termed the land ratio, which measures the percentage ratio of the land value to that of the overall property value $[40,41]$. The land ratio can be estimated by comparison on 
the basis of a simultaneous appraisal of market values for the land and the newly constructed buildings. It can also be derived from qualified market sources.

The market value of existing buildings can be considered the value of new buildings multiplied by an appropriate depreciation factor that estimates the real estate's physical and functional obsolescence. The depreciation factor can be easily assessed from major real estate market sources or by comparison. The expression (2) can be further modified as follows:

$$
\text { ip Vn a > S Vn b }
$$

where, in addition to the variables already defined, a represents the land ratio, Vn represents the unit market value of new buildings, and $\mathrm{b}$ is the depreciation factor.

The conditions that make demolition and reconstruction advantageous can be simplified by dividing both members by the value of the newly constructed real estate $(\mathrm{Vn})$. In this way, (3) becomes:

$$
\text { A ip a }>\mathrm{Sb}
$$

The building density of the existing assets, which is called it, can be defined by the ratio between the already built areas (S) and the area on which they stand (A). If you divide both members by the surface area, then (5):

$$
\text { ip } a>\text { it } b
$$

where it represents the area's current density ratio.

This condition may be further developed as follows (6):

$$
\text { ip/it }>\text { b/a }
$$

The economic conditions for demolition and reconstruction occur when the ratio ip/it-the area's potential densification determined by urban planning choices-exceeds the b/a ratio, which expresses the relationship between the buildings' residual value ratio and the land ratio.

This makes it possible to assess the economic feasibility of various urban transformation processes on the basis of just a few variables: the potential floor area ratio (FAR) determined by planning tools, the existing FAR, and the relationship between the buildings' residual value and the land ratio.

Intuitively, as the FAR set by planning tools increases and/or as the desirability of the asset's location rises, the possibilities for transformation through demolition and reconstruction increase.

The b/a ratio - which is normally greater than 1-determines the need to increase the FAR fixed by planning tools to create feasible conditions for demolition and reconstruction. The scrapping of the city almost systematically requires an increase in the density of areas to be transformed. This, in turn, makes it possible to consider the role of the model's other two variables, $b$ and it. As the existing density and/or the residual value of the assets increase(s), demolition and reconstruction become less feasible.

\section{The Real Estate Values Involved: The Model in Five Different Italian Cities}

Certain elaborations make it possible to estimate the quantitative importance of the values involved in formulating different redevelopment strategies. To this end, a selection was made among the cities of northern Italy, which is the country's most economically and socially dynamic area. This area is characterized by a network of high-density cities whose spatial concentration of people and businesses has enabled considerable economic and real estate development [25]. The territory includes economically and socio-demographically dominant cities, as well as small and medium-sized urban centers characterized by highly specialized functions.

Five Italian cities-Milan, Turin, Padua, Udine, and Novara-were selected. These cities represent an equal number of different economic and social situations characterized by specific real estate market dynamics, as evidenced in the data collected by the Italian revenue services' real estate market 
observatory (Agenzia delle Entrate, see Table 1). Some real estate quotations have not been taken over by the authoritative source of Agenzia delle Entrate since there have not been any sales or purchases of properties with similar characteristics in recent years. The absence of an adequate number of transactions to process is a clear sign of a weak real estate market.

Table 1. Real estate market trends in the five cities analyzed over the last ten years. Source: elaborations by the authors.

\begin{tabular}{|c|c|c|c|c|c|}
\hline & State of Conservation & Year & Center (€/sqm) & Semi-Center ( $€ /$ sqm) & Periphery ( $€ /$ sqm) \\
\hline \multirow{6}{*}{ Milan } & \multirow{3}{*}{ Excellent } & 2017 & 8200 & 4350 & 1975 \\
\hline & & 2007 & 6500 & 4000 & 1975 \\
\hline & & Var.\% & $26 \%$ & $9 \%$ & $0 \%$ \\
\hline & \multirow{3}{*}{ Used } & 2017 & 5400 & 3000 & 2000 \\
\hline & & 2007 & 3200 & 2530 & 2100 \\
\hline & & Var.\% & $69 \%$ & $19 \%$ & $-5 \%$ \\
\hline \multirow{6}{*}{ Turin } & \multirow[t]{2}{*}{ Excellent } & 2017 & 3119 & 2653 & 1856 \\
\hline & & 2007 & - & 2550 & 2175 \\
\hline & \multirow{4}{*}{ Used } & Var.\% & - & $-4 \%$ & $17 \%$ \\
\hline & & 2017 & 2357 & 2023 & 1469 \\
\hline & & 2007 & 2669 & 2490 & 1957 \\
\hline & & Var. $\%$ & $-13 \%$ & $-23 \%$ & $-33 \%$ \\
\hline \multirow{6}{*}{ Padua } & Excellent & 2017 & 3875 & 2315 & 1788 \\
\hline & \multirow{5}{*}{ Used } & 2007 & 3333 & - & 1800 \\
\hline & & Var. $\%$ & $-14 \%$ & - & $1 \%$ \\
\hline & & 2017 & 2544 & 1250 & 1100 \\
\hline & & 2007 & 2329 & 1570 & 1286 \\
\hline & & Var.\% & $9 \%$ & $-20 \%$ & $-14 \%$ \\
\hline \multirow{6}{*}{ Udine } & \multirow[t]{2}{*}{ Excellent } & 2017 & 2000 & - & - \\
\hline & & 2007 & - & - & - \\
\hline & \multirow{4}{*}{ Used } & Var.\% & - & - & - \\
\hline & & 2017 & 1500 & 1250 & 1100 \\
\hline & & 2007 & 1600 & 1500 & 1200 \\
\hline & & Var. \% & $-6 \%$ & $-17 \%$ & $-8 \%$ \\
\hline \multirow{6}{*}{ Novara } & Excellent & 2017 & - & - & - \\
\hline & \multirow{5}{*}{ Used } & 2007 & - & - & - \\
\hline & & Var. \% & - & - & - \\
\hline & & 2017 & 1044 & 777 & 906 \\
\hline & & 2007 & 1543 & 777 & 1223 \\
\hline & & Var. \% & $-32 \%$ & $0 \%$ & $-26 \%$ \\
\hline
\end{tabular}

The demographic and economic importance of these cities can be understood by referring to the DATAR classification [42]. This classification analyzes European urban agglomerations with more than 200,000 inhabitants on the basis of indicators related to certain internationally relevant functions and subsequently classifies them on one of seven levels, the hierarchy of which establishes each city's level of dynamism and competition within the overall context of Europe.

The first DATAR level refers to the only two European metropolises of world importance: Paris and London. The second relates to large urban centers characterized by important European infrastructures and multinationals. Milan is the only Italian city in this class. It is the major metropolis in northern Italy, and its demographic and economic indicators have continued to show a significant rise, which is reflected in the real estate market. With respect to the 2008 crisis, Milan is the only city among the five case studies to show an increase in real estate values. Only the suburban areas of Milan have remained stable, highlighting a preference for higher quality buildings in terms of services and accessibility.

The third DATAR level refers to large urban centers that are less economically competitive at a European level. The only Italian city among these cities is Rome, which was not analyzed because it is located outside the geographical boundaries of this analysis. The fourth level does not include any Italian cities and was subsequently not considered.

The fifth DATAR level includes large cities that, while not reaching the international importance of the prior levels, are renowned for at least one function of European importance. The city of Turin, which is the second most important metropolis in northern Italy, falls into this category. It is 
characterized by the automotive industry and by its competitiveness in the sectors of culture and food/wine. Although Turin is one of Italy's most important cities, it was significantly affected by the economic crisis of 2008. With the exception of new suburban construction, real estate values decreased significantly due to the general impoverishment of the city's population.

The sixth class includes all the cities that do not play an important role on a European level. This class includes the city of Padua, which, while not considered to be at a European level, is highly specialized given the presence of an important Italian university and numerous small and medium enterprises. The city's real estate market has been penalized by the social and economic dynamics of the last decade and shows a significant decline in property values, especially in the sector of new housing.

The last two case studies are not included in the DATAR classification because their population does not exceed 100,000 inhabitants. These cities-Udine and Novara-were selected to make this survey more complete and exhaustive, because municipalities with less than 90,000 inhabitants represent $99 \%$ of Italian cities [42-47]. Udine is the provincial capital of the extreme northeast of Italy and is located close to the inland areas of northern Friuli $[43,44]$. Novara is located in the northwest of Italy, and its economy is linked to companies and subsidiaries gravitating there as a satellite of Milan, which is less than 50 kilometers away. Even though they are minimally competitive on both a European and a national level, they are representative of many small- and medium-sized Italian cities. In both cities, the real estate market has experienced the territory's social and economic difficulties and shows a significant decline in values and in the amount of property traded.

\section{Data Analysis and Outcomes for the Model}

The elaborations concerned the right part of the inequality. The relationship between the real estate's residual value and the land pressure is what, in fact, determines the densification needed to make the demolition and reconstruction of buildings and neighborhoods economically viable.

The $b$ values were estimated through specific analysis models capable of generating property values on the basis of their construction attributes and positional characteristics.

In order to make the sample homogeneous, we selected only apartments, the most common residential typology in the five cities. We have excluded other types of buildings like villas, cottages, lofts, duplexes, attics, etc. Real estate websites do not provide the exact location of the dwellings. Nevertheless, real estate sales sites provide adequate information on the neighborhood, and therefore it was possible to identify the location distinguishing between the center, semi-center, and suburbs.

From the technological point of view, the classification distinguishes new construction and buildings to be renovated by recalling the commonly shared classification of supply and demand. The survey then distinguishes three areas for each city—center, semi-center and suburbs—relying once again on a consolidated market classification. The sample for each city included from 80 to 100 ask prices for residential properties and, as shown in Table 2, the sample tested is quite homogeneous. We also performed a Variance Inflation Factor to check for any multicollinearity between the variables. The tests pointed out negative results, confirming the quality of the models. Prices were discounted by a ratio based on the most reliable market sources [48] to keep the results as consistent as possible with effective market values.

In order to assess the variables, we used a hedonic price model. In the multiple regression model, the unit market value of the dwellings represents the dependent variable, while the state of conservation and the location of the dwellings represent the independent variables. The functional form of the regression model that maximizes the statistical performances is exponential, confirming the non-linearity of the value determination process. Through the hedonic price model $[49,50]$, we assessed the coefficient $b$. 
Table 2. Descriptive statistics for the market values of the five cities analyzed. Source: elaborations by the authors.

\begin{tabular}{|c|c|c|c|c|}
\hline & Variables & Ask Price (€/sqm) & State of Conservation & Location \\
\hline \multirow{6}{*}{ Milan } & Min & 2533.33 & 1 & 1 \\
\hline & $\operatorname{Max}$ & $14,583.33$ & 3 & 3 \\
\hline & Mean & 5900.60 & 1987.5 & $2,012.5$ \\
\hline & Variance & 8233.584 & 0.62 & 0.67 \\
\hline & Stand. dev & 2869.42 & 0.78 & 0.82 \\
\hline & Median & 5000 & 2 & 2 \\
\hline \multirow{6}{*}{ Turin } & Min & 694 & 1 & 1 \\
\hline & $\operatorname{Max}$ & 6054 & 3 & 3 \\
\hline & Mean & 2517.13 & 1.98 & 1.95 \\
\hline & Variance & 1749.577 & 0.67 & 0.65 \\
\hline & Stand. dev & 1322.71 & 0.82 & 0.81 \\
\hline & Median & 2277 & 2 & 2 \\
\hline \multirow{6}{*}{ Padua } & Min & 7373.737 & 1 & 1 \\
\hline & $\operatorname{Max}$ & 3652.174 & 3 & 3 \\
\hline & Mean & 1793.22 & 2 & 2 \\
\hline & Variance & 4698.014 & 0.67 & 0.67 \\
\hline & Stand. dev & 6854.206 & 0.82 & 0.82 \\
\hline & Median & 1700.89 & 2 & 2 \\
\hline \multirow{6}{*}{ Udine } & Min & 5525 & 1 & 1 \\
\hline & $\operatorname{Max}$ & 2302.08 & 3 & 3 \\
\hline & Mean & 1232.09 & 1.95 & 2075 \\
\hline & Variance & 2011.543 & 0.53 & 0.63 \\
\hline & Stand. dev & 44,850 & 0.71 & 0.79 \\
\hline & Median & 1105.51 & 2 & 2 \\
\hline \multirow{6}{*}{ Novara } & Min & $6,744.186$ & 1 & 1 \\
\hline & Max & 3333.33 & 3 & 3 \\
\hline & Mean & 1569.13 & 0.08 & 0.09 \\
\hline & Variance & 3775.836 & 0.68 & 0.68 \\
\hline & Stand. dev & 61,448 & 0.82 & 0.82 \\
\hline & Median & 1404.96 & 2 & 2 \\
\hline
\end{tabular}

The tests relating to the reliability of the hedonic prices we looked for are definitely satisfactory (see Table 3).

The hedonic prices that emerged from the analysis highlight completely different real estate markets and reflect the values emerging from real estate research through indirect sources (see Table 4).

In order to determine the variable $b$ of the model, nine mean unit market values were assessed as a function of the city. The following characteristics were considered: newly built dwellings, used dwellings, and dwellings to be restructured, respectively located in the center, semi-center, and the suburbs. Secondly, $\mathrm{b}$ was estimated through the ratio of the new dwellings' market values in the respective locations. The values of $b$ for newly built apartments, therefore, are equal to one and were therefore not taken into account.

The elaborations show that the $b$ value of the properties to be renovated never falls below $41 \%$ of their original value for all the cities and, in Milan, reaches a considerably higher percentage of $72 \%$ (see Table 5).

The values of the land ratio, as shown in Table 6, were calculated on the basis of an authoritative source (Il Sole-24 Ore's "Il Consulente Immobiliare"). With the exception of Milan and to a lesser extent Turin, the values of the variable reflect a market dynamic that does not seem significant at this stage. 
Table 3. Market values regression models for the five cities. Source: elaborations by the authors.

\begin{tabular}{|c|c|c|c|c|c|}
\hline & Parameter & Appraisal & Standard & $\mathbf{T}$ & $p$-Value \\
\hline \multirow{3}{*}{ Milan } & Constant & 7.89 & 0.03 & 297.44 & 0.00 \\
\hline & $\begin{array}{c}\text { Conservation } \\
\text { status }\end{array}$ & 0.16 & 0.02 & 9.59 & 0.00 \\
\hline & Localization & 0.52 & 0.02 & 31.74 & 0.00 \\
\hline \multicolumn{6}{|c|}{ R2 93.7\%; R2 (adapted per g.l.) 93.5\%; Standard errors 0.11900} \\
\hline \multirow{3}{*}{ Turin } & Constant & 6.78 & 0.03 & 258.58 & 0.00 \\
\hline & $\begin{array}{c}\text { Conservation } \\
\text { status }\end{array}$ & 0.44 & 0.02 & 28.15 & 0.00 \\
\hline & Localization & 0.45 & 0.02 & 28.42 & 0.00 \\
\hline \multicolumn{6}{|c|}{ R2 94.3\%; R2 (adapted per g.1.) 94.2\%; Standard errors 0.12669} \\
\hline \multirow{3}{*}{ Padua } & Constant & 6.79 & 0.021 & 330.22 & 0.00 \\
\hline & $\begin{array}{c}\text { Conservation } \\
\text { status }\end{array}$ & 0.35 & 0.013 & 27.54 & 0.00 \\
\hline & Localization & 0.29 & 0.013 & 22.65 & 0.00 \\
\hline \multicolumn{6}{|c|}{ R2 92.4\%; R2 (adapted per g.1.) 92.2\%; Standard errors 0.10682} \\
\hline \multirow{3}{*}{ Udine } & Constant & 6.45 & 0.05 & 126.15 & 0.00 \\
\hline & $\begin{array}{c}\text { Conservation } \\
\text { status }\end{array}$ & 0.45 & 0.03 & 14.60 & 0.00 \\
\hline & Localization & 0.16 & 0.03 & 5.96 & 0.00 \\
\hline \multicolumn{6}{|c|}{ R2 73.9\%; R2 (adapted per g.1.) 73.2\%; Standard errors 0.18676} \\
\hline \multirow{3}{*}{ Novara } & Constant & 6.68 & 0.02 & 319.94 & 0.00 \\
\hline & $\begin{array}{c}\text { Conservation } \\
\text { status }\end{array}$ & 0.41 & 0.01 & 32.30 & 0.00 \\
\hline & Localization & 0.19 & 0.01 & 14.58 & 0.00 \\
\hline
\end{tabular}

Table 4. Market values by location and building quality. Source: elaborations by the authors.

\begin{tabular}{ccccc}
\hline City & Building Quality/Location & Center (€/sqm) & Semi-Center $(\mathbf{\epsilon} / \mathbf{s q m})$ & Periphery (€/sqm) \\
\hline \multirow{3}{*}{ Milan } & to be restructured & 7518 & 4469 & 2657 \\
& used & 8848 & 5261 & 3128 \\
\multirow{4}{*}{ Turin } & new & 10,415 & 6192 & 3681 \\
& to be restructured & 2154 & 1377 & 1366 \\
& used & 3341 & 2137 & 2120 \\
Padua & new & 5182 & 3314 & 887 \\
& to be restructured & 1569 & 1180 & 1255 \\
& used & 2219 & 1669 & 1776 \\
Udine & new & 3140 & 2361 & 633 \\
& to be restructured & 878 & 745 & 990 \\
& used & 1375 & 1167 & 1550 \\
Novara & new & 2152 & 1826 & 796 \\
& to be restructured & 1155 & 959 & 1202 \\
& used & 1744 & 1448 & 1815 \\
\hline
\end{tabular}

The land ratios vary considerably in accordance with the quality of the area's position, reaching the highest value in the central areas and decreasing in the peripheral areas. In the central areas, for example, the ratio of the land component in the market value ranges from a maximum of $44 \%$ in Milan to $10 \%$ in peripheral areas of Novara (see Table 4). 
Table 5. The values of $\mathrm{b}$ according to the levels of obsolescence. Source: elaborations by the authors.

\begin{tabular}{|c|c|c|}
\hline City & Variables & Value \\
\hline \multirow{2}{*}{ Milan } & $\mathrm{b}$ to be renovated & 0.72 \\
\hline & b used & 0.84 \\
\hline \multirow{2}{*}{ Turin } & $\mathrm{b}$ to be renovated & 0.42 \\
\hline & b used & 0.64 \\
\hline \multirow{2}{*}{ Padua } & $\mathrm{b}$ to be renovated & 0.50 \\
\hline & b used & 0.71 \\
\hline \multirow{2}{*}{ Udine } & $\mathrm{b}$ to be renovated & 0.41 \\
\hline & b used & 0.64 \\
\hline \multirow{2}{*}{ Novara } & $\mathrm{b}$ to be renovated & 0.44 \\
\hline & b used & 0.66 \\
\hline
\end{tabular}

Table 6. Land ratios for the cities analyzed. Source: elaborations by the authors.

\begin{tabular}{cccc}
\hline City & Center & Semi-Center & Periphery \\
\hline Milan & 0.44 & 0.33 & 0.25 \\
Turin & 0.33 & 0.23 & 0.17 \\
Padua & 0.27 & 0.18 & 0.15 \\
Udine & 0.20 & 0.14 & 0.12 \\
Novara & 0.18 & 0.13 & 0.10 \\
\hline
\end{tabular}

On the basis of the $b$ and a values, it is possible to identify the density multipliers necessary to make the demolition and reconstruction processes feasible. The ratio is minimal where the buildings in central areas have reached the highest level of obsolescence. If the maximum speculative pressure occurs with the minimum residual value, the multiplicative ratio is at its lowest values. On the basis of the elaborations carried out, it varies from a minimum of 1.6 for Milan to 2.4 for Novara, where the market is less active, due to the different land pressure that inevitably distinguishes the different cities according to their size and attractiveness.

At the opposite end of the spectrum, the ratio will be at its maximum if the land pressure is minimal, as in the suburbs, and if the assets maintain a significant residual value. If we consider how much volume is necessary to carry out demolition and reconstruction work in the suburbs, on the basis of used but perfectly fungible assets, the multiplicative coefficients of the existing density become important. In the peripheral areas of Milan, for example, the density must be multiplied by 3.4. However, the value becomes even more important when the land component has less value, as in Turin, where the multiplier is equal to 3.8; in Padua, where it is equal to 4.7; in Udine, where it reaches almost 5.3; or in Novara, where it reaches a maximum value of 6.6.

In the middle, values tend to range between the thresholds noted, based on the assets' age and the desirability of their location. In the semi-central areas of Milan, the multiplicative coefficients required oscillate between 2.2 and 2.6 times the existing density based on the quality of the building. In Novara, sustainable demolition and reconstruction covers a range that requires the density of the oldest buildings to be tripled and that of new buildings to be increased fivefold (see Table 7). 
Table 7. The value of b/a according to location and building quality. Source: elaborations by the authors.

\begin{tabular}{|c|c|c|c|c|}
\hline City & Building Quality & Center & Semi-Center & Periphery \\
\hline \multirow{2}{*}{ Milan } & To be renovated & 1.64 & 2.19 & 2.89 \\
\hline & Used & 1.93 & 2.57 & 3.40 \\
\hline \multirow{2}{*}{ Turin } & To be renovated & 1.26 & 1.81 & 2.44 \\
\hline & Used & 1.95 & 2.80 & 3.79 \\
\hline \multirow{2}{*}{ Padua } & To be renovated & 1.85 & 2.78 & 3.33 \\
\hline & Used & 2.62 & 3.93 & 4.71 \\
\hline \multirow{2}{*}{ Udine } & To be renovated & 2.04 & 2.92 & 3.40 \\
\hline & Used & 3.19 & 4.56 & 5.32 \\
\hline \multirow{2}{*}{ Novara } & To be renovated & 2.44 & 3.37 & 4.39 \\
\hline & Used & 3.68 & 5.09 & 6.62 \\
\hline
\end{tabular}

\section{The Exception and The Rule: Why Retrofit is Going to Be Crucial for The Regeneration of Real Estate Assets}

The conditions for regenerating the city through the demolition of existing buildings seem to be limited to specific parts of the city. The elaborations carried out in this study show how the demolition and reconstruction of urban areas or individual buildings are only economically viable for landowners where urban planning provisions permit significant increases in the existing volume. While this may be possible in the case of underused areas, such as warehouses or similar structures that are in disuse or in the process of being abandoned, it is unlikely that these conditions will be met in the prime peripheral areas of our cities, which are normally denser and have functions that the market still considers attractive.

The assessment of the economic feasibility of demolition and reconstruction operations also needs to be calibrated on the basis of the location's importance. In large metropolitan centers, of which Milan is an emblematic sample city, the demolition and reconstruction of buildings and neighborhoods is certainly more likely than in small- and medium-sized cities. The difference in the pressure of demand, which reaches its maximum in the large metropolitan poles and minimum in the smaller localities of Italy, determines a demand pressure that has a significant influence on model values. In the central and semi-central areas of Milan therefore, land expectations and residual low-density areas undoubtedly favor urban transformation processes based on the replacement of buildings and urban sectors.

In small- and medium-sized towns, maximum b/a multipliers highlight the lack of fundamentals of demand. This is the basis of land values that make particularly significant increases in necessary density. In the cases examined - in particular, in the cities of Padua, Novara, and Udine, which are representative of small- and medium-sized cities-these values can reach important thresholds, the predictability of which are often called into question by a multitude of concurrent factors.

One factor is density, which is often not contained. In the areas that expanded during the 1950s and 1960s, the densities established by planning guidelines were often considerable and make replacement strategies difficult, simply because the multiplication of volumes cannot be met by a multiplication of demand. These cities have had difficulty maintaining their population levels for some time given an increase in the average age of the population and a consequent reduction in the number of people purchasing new housing.

Yet, even if one were to abstractly assume a solvent demand for the purchase of newly replaced real estate assets, the settlement load would be multiplied several times without a corresponding increase in the quality and quantity of the stock of fixed social capital, with considerable consequences for collective costs and negative externalities [49]. It is not merely by chance that one of the most important urban demolition and reconstruction projects in Italy is in the area of Milan's Garibaldi station, where the high collective investment in infrastructure corresponds to an equally high density of private uses [25]. 
Finally, it is useful to underline how areas of regeneration are characterized by fragmented ownership, resulting from decades of housing policies that have systematically promoted access to home ownership. Although the transaction costs inherent in urban replacement processes were deliberately excluded from this model, they nonetheless contribute to making this sort of development model more fragile, especially in the case of interventions in areas characterized by medium and high settlement densities, which tend to be composed of dozens of properties for which priorities are often dissimilar [51,52].

The redevelopment processes of most of Italian suburbs, especially those outside of large metropolitan centers, involve the regeneration of existing assets without the easy illusion of radically replacing the public and private sections of the city. The challenge lies in the ability to redesign and upcycle what remains of assets that are clearly obsolete but are still characterized by a value that makes their demolition and reconstruction unlikely.

The use of the energy and the material contained in existing assets makes it possible to pursue goals of public and private interest. The protection and enhancement of assets corresponds to a development strategy that is more consistent with the principles of the circular economy $[26,28,31]$.

\section{Conclusions}

There are many different strategies for redeveloping the public and private assets of cities, the viability of which depends upon economic feasibility and the subsequent advantages to property owners and developers. This study has sought to compare the economic conditions of the two most widely considered options: the demolition and reconstruction of buildings, and sections of the city and the redevelopment of existing assets.

The model we proposed makes it possible evaluate the benefits of a property's demolition and reconstruction in accordance with specific urban planning provisions. Particular characteristics of existing assets (land value and state of obsolescence) make it possible to determine the feasibility of demolition and reconstruction by verifying whether the increase in existing density is sufficient: the higher the ratio between the assets' residual and land values, the greater the multiplier of the existing building density and vice versa.

The real estate values of five northern Italian cities then made it possible to test the model and interpret the results. Five cities differently ranked by size and territorial relevance were compared to verify whether, and in what forms, real estate values and urban planning provisions could give rise to advantageous systems that might justify either demolition and reconstruction or the redevelopment of specific assets.

The results show an important variation of the densification coefficient. In the center of Milan, the only true metropolitan city we had the opportunity to examine, a modest increase in density creates conditions that are favorable to demolition and reconstruction. In the other cities, whose relevance is minor compared to Milan, the density multiplier coefficient becomes considerably higher, especially if we consider outskirt areas, and the buildings still have a significant residual value.

In the light of these results, a large part of the peripheral areas-especially in small- and medium-sized cities-are constrained to regenerate their public and private assets without being able to count on radical transformations of properties and neighborhoods. The increase in existing density seems incompatible with both the characteristics of real estate market, in which demand is still low, and the fact that existing infrastructures and public facilities cannot absorb the vast new supply of building units a demolition/reconstruction project would theoretically require.

While, theoretically, the reasons for redeveloping existing assets are not lacking, the situation regarding assessment of the technologies available for the redevelopment of older buildings is different. With current technologies, time and cost could be significant. Despite demand, investors could be poorly inclined to invest because of potentially long, uncertain timescales and prices, which are costly and often comparable to those of new construction $[5,21,27]$. 
It is not surprisingly, therefore, that several European countries are trying to tackle the long-standing problem of low productivity in the construction industry with solutions aimed at greater efficiency and thus lower costs, to ensure a wider spectrum of highly profitable investment in the real estate market $[33,34,53]$. Without adequate investment in new processes and products, current technologies could limit regeneration processes, leading to an increasingly significant obsolescence of real estate assets with economic and social consequences, which it would be superficial to consider marginal.

Modernizing the building industry seems decisive in increasing productivity and therein making retrofitting costs more accessible to a demand that will likely find it difficult to commit considerable financial resources toward building interventions. A renewed commitment to productivity and innovation in the construction industry could not only make the regeneration and redevelopment of the many urban areas facing obsolescence less generic and less dependent on public resources; it might also make the forms of intervention as consistent as possible with objectives of sustainable development and the circular economy.

Future research will be able to extend the survey territory by applying the theoretical model to other Italian cities, especially those in the south of Italy, in order to measure possible divergences between the results of this research or to further confirm the conclusions of the paper. Furthermore, further investigation could concern the other European cities.

Author Contributions: Conceptualization, E.M.; methodology, E.M., A.M.; software, A.M.; validation, A.M., formal analysis, E.M.; investigation, E.M., A.M.; resources, E.M.; data curation, A.M.; writing-original draft preparation, E.M., A.M.; writing—review and editing, E.M., A.M.; supervision, E.M.; project administration, E.M.; funding acquisition, E.M. All authors have read and agreed to the published version of the manuscript.

Funding: This research was funded by Ministero dell'Istruzione, dell'Università e della Ricerca, grant number PRIN 2015 protocol 2015STFWFJ_004.

Conflicts of Interest: The authors declare no conflict of interest.

\section{References}

1. Itard, L.; Meijer, E.; Vrins, H.; Hoiting, H. Building Renovation and Modernisation in Europe: State of the Art Review; TU Delft: Delft, The Netherlands, 2018.

2. Quale, J.; Eckelman, M.J.; Williams, K.W.; Sloditskie, G.; Zimmerman, J.B. Construction Matters. J. Ind. Ecol. 2012, 16, 243-253. [CrossRef]

3. Addis, W.; Schouten, J. Design for Deconstruction: Principles of Design to Facilitate Reuse and Recycling; CIRIA: London, UK, 2004.

4. Micelli, E. L'eccezione e la regola. Le forme della riqualificazione della città esistente tra demolizione e ricostruzione e interventi di riuso. Valori Valutazioni 2014, 12, 11-20.

5. Micelli, E.; Mangialardo, A. Recycling the City. New perspective on the real-estate market and construction industry. In Smart and Sustainable Planning for Cities and Regions; Bisello, A., Vettorato, D., Stephens, R., Eds.; Green Energy and Technology; Springer International Publishing AG: Cham, Switzerland, 2017.

6. Burchell, R.W.; Downs, A.; McCann, B.; Mukherji, S. Sprawl Costs: Economic Impacts of Unchecked Development; Island Press: Washington, DC, USA, 2005.

7. Ewing, R. Is Los Angeles-style sprawl desirable? J. Am. Plan. Assoc. 1997, 63, 107-126. [CrossRef]

8. Ewing, R. Characteristics causes and effects of sprawl: A literature review. Environ. Urban Stud. 1994, 21, $1-15$.

9. Speir, C.; Stephenson, K. Does sprawl cost us all? Isolating the effects of housing patterns on public water and sewer costs. J. Am. Plan. Assoc. 2002, 68, 56-70. [CrossRef]

10. Stone, B. Urban sprawl and air quality in large UC cities. J. Environ. Manag. 2008, 86, 688-698. [CrossRef]

11. Song, Y.; Liu, C.; Langston, C. Exploring intersectoral linkages between real estate and construction. Int. J. Constr. Manag. 2008, 8, 73-83. [CrossRef] 
12. Mangialardo, A.; Micelli, E. Rethinking the construction industry under the circular economy: Principles and case studies. In Smart and Sustainable Planning for Cities and Regions; Bisello, A., Vettorato, D., Laconte, P., Costa, S., Eds.; Green Energy and Technology; Springer International Publishing AG: Cham, Switzerland, 2018.

13. Newman, P.W.G.; Kenworthy, J.R. Urban design to reduce automobile dependence. Opolis Int. J. Suburb. Metrop. Stud. 2006, 2, 35-52.

14. Power, A. Housing and sustainability: Demolition or refurbishment? Urban Des. Plan. 2010, 163, $205-216$. [CrossRef]

15. Owen, D. Why Living Smaller, Living Closer, and Driving Less Are the Keys to Sustainability; Riverhead Books: New York, NY, USA, 2009.

16. Johnson, M.; Hollander, J.; Hallulli, A. Maintain demolish, re-purpose: Policy design for vacant land management using decision models. Cities 2014, 40, 151-162. [CrossRef]

17. McDonough, W.; Braungart, M.; Clinton, B. The Upcycle: Beyond Sustainability-Designing for Abundance; North Point Press: New York, NY, USA, 2013.

18. Elefante, C. The greenest building is ... one that is already built. Forum J. Natl. Trust Hist. Preserv. 2012, 27, 62-72.

19. Assefa, G.; Ambler, C. To demolish or not to demolish: Life cycle consideration of repurposing buildings. Sustain. Cities Soc. 2017, 28, 146-153. [CrossRef]

20. Bullen, P.A.; Love, P.E.D. The rhetoric of adaptative reuse or reality of demolition: Views from the field. Cities 2010, 27, 215-224. [CrossRef]

21. Power, A. Does demolition or refurbishment of old and inefficient homes help to increase our environmental, social and economic viability? Energy Policy 2008, 36, 4487-4501. [CrossRef]

22. Thomsen, A.; van der Flier, K. Replacement or reuse? The choice between demolition and life cycle extension from a sustainable viewpoint. In Shrinking Cities, Sprawling Suburbs, Changing Countrysides, Proceedings of the ENHR Conference, Dublin, Ireland, 28 June-3 July 2008; Norris, M., Slike, D., Eds.; Centre for Housing Research: Glasgow, UK, 2008.

23. Dixit, M.K.; Fernàndez-Solìs, L.S.; Lavy, S.; Culp, C.H. Identification parameters for embodied energy measurement: A literature review. Energy Build. 2010, 42, 1238-1247. [CrossRef]

24. Gaspar, P.L.; Santos, A.L. Embodied energy on refurbishment vs. demolition: A southern Europe case study. Energy Build. 2015, 87, 386-394. [CrossRef]

25. Power, A. Sustainable Communities and Sustainable Development: A Review of the Sustainable Communities Plan; CASE Report 23; Centre for Analysis of Social Exclusion: London, UK, 2005.

26. Andersen, M.S. An introductory note on the environmental economics of the circular economy. Sustain. Sci. 2007, 2, 133-140. [CrossRef]

27. Mangialardo, A.; Micelli, E.; Saccani, F. Does Sustainability affect real estate market values? Empirical evidence from the Office Buildings market in Milan (Italy). Sustainability 2018, 11, 12. [CrossRef]

28. Chesire, D. Building Renolutions-Applying the Circular Economy to the Built Environment; Riba Publishing: London, UK, 2017.

29. ARUP. The Circular Economy in the Built Environment. 2016. Available online: http://publications.arup. com/publications/c/circular_economy_in_the_built_environment (accessed on 15 December 2018).

30. Foster, G. Circular economy strategies for adaptive reuse of cultural heritage buildings. Resour. Conserv. Recycl. 2020, 152, 104507. [CrossRef]

31. Thornton, B.J. The greenest building (is the one that you don't build!) effective techniques for sustainable adaptive reuse/renovation. J. Green Build. 2011, 6, 1-7. [CrossRef]

32. D'Alpaos, C.; Bragolusi, P. Buildings energy retrofit valuation approaches: State of the art and future perspectives. Valori Valutazioni 2018, 20, 79-94.

33. Gyourko, J.; Saiz, A. Urban decline and housing reinvestment: The role of construction costs and the supply side. Fed. Reserve Bank Phila. 2004, 3, 1-55.

34. Stas, N. The Economics of Adaptative Reuse of Old Buildings: A Financial Feasibility Study \& Analysis. Master's Thesis, University of Waterloo, Waterloo, ON, Canada, 2007.

35. Vardopoulos, I. Critical sustainable development factors in the adaptative reuse of urban industrial buildings. A fuzzy DEMATEL approach. Sustain. Cities Soc. 2019, 50, 101684. [CrossRef]

36. Nesticò, A.; Sica, F. The sustainability of urban renewal projects: A model for economic multi-criteria analysis. J. Prop. Investig. Financ. 2017, 35, 397-409. [CrossRef] 
37. Aigwi, I.E.; Egbelakin, T.; Ingham, J. Efficacy of adaptive reuse for the redevelopment of underutilized historical buildings: Towards the regeneration of New Zealand's provincial town centers. Int. J. Build. Pathol. Adapt. 2018, 36, 385-407. [CrossRef]

38. Bisello, A.; Antoniucci, V.; Marella, G. Measuring the price premium of energy efficiency: A two-step analysis in the Italian housing market. Sustainability 2020, 208, 109670. [CrossRef]

39. Mangialardo, A.; Micelli, E. La partecipazione crea valore? Modelli di simulazione per la valorizzazione dal basso del patrimonio immobiliare pubblico. Valori Valutazioni 2017, 19, 1-12.

40. Camagni, R. Il finanziamento della città pubblica: La cattura dei plusvalori fondiari e il modello perequativo. In Urbanistica e Fiscalità Locale: Orientamenti di Riforma e Buone Pratiche in Italia e All'estero; Curti, F., Ed.; Maggioli: Rimini, Italy, 1999.

41. Realfonzo, A. Teoria e Metodo Dell'estimo Urbano; La Nuova Italia Scientifica: Roma, Italy, 1994.

42. Rozenblat, C. European urban polycentrism: A multiscale typology. Geogr. Helv. 2009, 64, 175-185. [CrossRef]

43. Inu, Tratti Strutturali dei Comuni Italiani. 2017. Available online: http://www.rapportodalterritorioinu.it/ 2005/Pagine\%20separate/Tratti_strutturali.pdf (accessed on 21 January 2019).

44. Valier, A. Le architetture del fallimento. Strategie e tecniche per il riuso dei progetti incompiuti. Territorio 2019, 87, 113-121. [CrossRef]

45. Canesi, R.; Marella, G. Residential construction costs: An Italian case study. Int. J. Appl. Eng. Res. 2017, 12, 2623-2634.

46. Punziano, G.; Urso, G. Local development strategies for inner areas in Italy. A comparative analysis based on plan documents. Ital. J. Plan. Pract. 2016, 6, 76-109.

47. Pose, R.A. The revenge of the places that don't matter (and what to do about it). Camb. J. Reg. Econ. Soc. 2018, 11, 189-209. [CrossRef]

48. Nomisma. Osservatorio Sul Mercato Immobiliare; Nomisma: Bologna, Italy, 2018.

49. Michieli, I.; Michieli, M. Trattato di Estimo; Edagricole: Milan, Italy, 2006.

50. Roscelli, R. Mercato Immobiliare, Innovazione e Gestione dei Catasti Urbani; Ceset: Florence, Italy, 2002.

51. Brown, D. Business models for residential retrofit in the UK: A critical assessment of five key archetypes. Energy Effic. 2018, 11, 1-21. [CrossRef]

52. Jensen, P.A.; Maslesa, E.; Berg, J.B.; Thuesen, C. 10 questions concerning sustainable building renovation. Build. Environ. 2018, 143, 130-147. [CrossRef]

53. Farmer, M. Modernise or Die; Construction Leadership Council: London, UK, 2016. 